\title{
POTENCIALIDADES, DESAFIOS E DIFICULDADE DE ENSINAR GEOMETRIA POR MEIO DAS TECNOLOGIAS DIGITAIS
}

\author{
Thiago Avila Pouzada \\ Universidade Federal do Rio Grande - FURG \\ thiago.pouzada@gmail.com \\ Tanise Paula Novello \\ Universidade Federal do Rio Grande - FURG \\ tanisenovello@furg.br \\ Luana Maria Santos da Silva Ayres \\ Universidade Federal do Rio Grande - FURG \\ luana ayres@,furg.br \\ Fabrine Diniz Pereira \\ Universidade Federal de Pelotas - UFPel \\ fabrinediniz@hotmail.com
}

\section{Resumo}

A Geometria é um conteúdo importante no campo da Matemática, sendo o ensino desta o ponto de partida de diversas problematizações no âmbito educacional. Este artigo tem como objetivo compreender, através do discurso de professores de Matemática, as potencialidades, desafios e dificuldades da utilização das tecnologias digitais para ensinar Geometria. Para tanto, analisou-se atividades desenvolvidas com professores de Matemática na disciplina de Geometria Analítica e Dinâmica no curso de Especialização em Matemática ofertado pela Universidade Federal do Rio Grande - FURG, na modalidade a distância. A análise foi feita a partir da leitura das interações dos professores em três atividades propostas, resultando em uma categorização organizada em dois tópicos: o primeiro tratando das tecnologias digitais no ensino de Geometria, trazendo as potencialidades, desafios e dificuldades presentes; e o segundo abordando os conceitos, construções e abstrações presentes no ensino de Geometria. Salienta-se que nessa escrita será abordado somente o primeiro tópico. Através da análise, percebeu-se que é essencial a contextualização da Geometria, e que esta pode ser realizada utilizando recursos tecnológicos em sala de aula para auxiliar no aprender, mas para tanto repensar a formação inicial do professor é fundamental; além disso, é fundamental uma formação inicial adequada para os professores.

Palavras-chave: Ensinar Geometria; Professores de Matemática; Tecnologias Digitais.

\begin{abstract}
Geometry is an important content in the field of mathematics, and its teaching is the starting point of several problematizations in the educational field. This article aims to understand, through the discourse of mathematics teachers, the potentialities, challenges and difficulties of using digital technologies to teach geometry. For that, we analyzed activities developed with Mathematics teachers in the discipline of Analytical and Dynamic Geometry in the Mathematics Specialization course offered by the Federal University of Rio Grande - FURG, in the distance modality. The analysis was made by reading the interactions of teachers in three proposed activities, resulting
\end{abstract}


in a categorization organized in two topics: the first dealing with digital technologies in the teaching of geometry, bringing the potentialities, challenges and difficulties present; and the second addressing the concepts, constructions and abstractions present in the teaching of geometry. Note that this writing will only address the first topic. Through the analysis, it was realized that the contextualization of Geometry is essential, and that it can be done using technological resources in the classroom to assist in learning, but to rethink the initial formation of the teacher is fundamental; In addition, adequate initial training for teachers is essential.

Palavras-chave: Ensinar Geometria; Professores de Matemática; Tecnologias Digitais.

\section{INTRODUÇÃO}

A Matemática é uma ciência que tem aplicações em muitas áreas e está presente no cotidiano das pessoas, direta ou indiretamente. Por esse motivo, por mais que seja um ramo do conhecimento pouco adorado, muito pelo mito criado de que a Matemática é essencialmente difícil e parece não fazer sentido, não há como ignorar a sua importância na evolução da humanidade.

Desta forma, é imprescindível que o ensino de Matemática esteja de acordo com as necessidades sociais da era atual. É importante que o processo de ensinar busque contextualização, aproximando o estudante da sua realidade e visando a aprendizagem, a partir da ideia de que tudo o que se estuda em Matemática tem uma razão própria para assim ser feito e uma importância particular no nosso dia-a-dia.

No contexto da Matemática, um dos conteúdos que mais tem aplicações diretas e relações com outros conteúdos na própria disciplina é a Geometria. As construções geométricas estão presentes desde os primórdios da humanidade, sendo fundamentais os conhecimentos construídos pelos povos antigos para a base Matemática que se tem atualmente.

Sendo a Geometria um ramo tão expressivo do conhecimento, ela precisa ser tratada com uma atenção especial, no que diz respeito ao seu ensino. Lorenzato (1995) afirma que o ensino de Geometria tem sido deixado de lado nas escolas, problematizando que os professores têm deixado de lado as construções geométricas em prol de outros conteúdos matemáticos, julgados mais importantes. Considerando tal importância, a formação continuada de professores de Matemática deve se preocupar com o ensinar da Geometria.

Nesse sentido, este trabalho tem como objetivo compreender, através do discurso de professores de Matemática as potencialidades, os desafios e as dificuldades da utilização das tecnologias digitais para ensinar Geometria. Para tanto, este estudo foi desenvolvido com professores de Matemática que cursavam a disciplina de Geometria 
Analítica e Dinâmica do curso de Especialização em Matemática ofertado pela Universidade Federal do Rio Grande - FURG.

A análise foi feita a partir das interações dos professores em fóruns de discussão, como parte da avaliação feita pela disciplina. Foram escolhidas três atividades que problematizaram o ensinar da Geometria: a primeira atividade questionou os professores a respeito das suas concepções sobre o uso de tecnologias digitais para ensinar Geometria, além de questionar se a construção geométrica feita no papel seria diferente da construção geométrica utilizando um software; a segunda atividade problematizou um erro em uma construção geométrica a partir de um software, questionando os professores sobre qual seria a origem do erro; e a terceira atividade partiu da afirmação de Lorenzato (1995) de que o ensino de Geometria seria deixado de lado nas escolas em prol de outros conteúdos matemáticos.

\section{UMA APROXIMAÇÃO AO TEMA: GEOMETRIA E TECNOLOGIAS}

$\mathrm{O}$ ato de ensinar Geometria, assim como o de ensinar Matemática, é bastante complexo, pois um bom ensinar envolve uma série de fatores. Entre eles, pode-se citar, por exemplo: formação inicial qualificada dos professores no contexto da Geometria; preocupação dos mesmos para com os alunos e turmas, uma vez que cada situação deve ser tratada individualmente; condições físicas e estruturais da escola; entre outros.

Nesse sentido, tecnologias digitais surgem como uma possibilidade aliada ao ensinar Geometria, pois permitem aos alunos manipular as construções geométricas e podem propiciar a visualização e experienciação de conceitos matemáticos. Elas complementam tecnologias mais tradicionais, como o lápis, régua e compasso, pois a interatividade manipulativa propicia uma melhor compreensão por parte dos alunos, fugindo da abstração geométrica presente no material concreto.

Buscando evidenciar a importância do uso das tecnologias digitais no ensino de Geometria, foi feita uma busca em algumas revistas e encontros de Educação Matemática, através de palavras-chave relacionadas com Geometria e tecnologias no ensino de Geometria. Desta forma, apresenta-se alguns autores e resumidamente os seus trabalhos e vivências utilizando tecnologias e softwares educacionais relacionados à Geometria.

Carlos e Müller (2013) apresentam um estudo que defende a contribuição do software GeoGebra na aprendizagem dos conceitos geométricos no estudo das pirâmides em uma turma de Ensino Médio, abordando a relação existente entre a informática e a Educação Matemática. As autoras realizaram observações em uma pesquisa qualitativa, 
problematizando as contribuições do GeoGebra na aprendizagem significativa dos seus alunos.

Nascimento (2012) propôs a utilização de novas tecnologias para auxiliar o Ensino de Matemática a partir de uma pesquisa experimental. Foram apresentados aos alunos e professores de Matemática que participaram da pesquisa os recursos e a potencialidade do GeoGebra para auxiliar no ensino de Geometria, refletindo em uma grande aceitação por parte dos mesmos.

Idem (2016) buscou identificar os conhecimentos mobilizados por professores e graduandos de Licenciatura em Matemática envolvidos em um curso de formação, no qual os participantes exploraram atividades de Geometria Plana e Espacial, utilizando o software GeoGebra. O curso propiciou a mobilização de conhecimentos docentes, conceituais e tecnológicos, envolvendo atividades com o software e entrevistas com os participantes.

Leite e Oliveira (2016) realizaram uma pesquisa qualitativa que teve como sujeitos graduandos de Licenciatura em Matemática. A investigação, organizada em torno dos pressupostos do Technological Pedagogical Content Knowledge (TPCK), objetivou identificar de que forma os potenciais professores de Matemática se apropriam de conhecimentos relativos ao Teorema de Tales, dos pontos de vista epistemológico e didático, considerando o uso de tecnologias digitais (em específico, o software GeoGebra).

Cotic (2012) expôs uma experiência na capacitação de um grupo de graduandos em Matemática que participaram de um curso de GeoGebra, objetivando a transferência dos seus conhecimentos específicos e metodológicos aos alunos. Foram apresentadas algumas atividades sequenciais, como parte de um estudo mais complexo sobre o saber geométrico que é gerado em sala de aula.

Nascimento et. al. (2015) apresentou algumas experiências vivenciadas no contexto escolar utilizando o software GeoGebra no estudo introdutório da Geometria Analítica. Os seus resultados indicaram que o GeoGebra viabiliza uma compreensão conceitual mais aguçada, estimulando o interesse e a curiosidade dos estudantes, apontando para a importância da presença dos recursos tecnológicos no exercício docente, no planejamento e delineamento de atividades mais dinâmicas e diversificadas.

Santos et. al. (2015) realizou algumas oficinas com o GeoGebra, com alunos do Ensino Fundamental e Médio, apresentando alguns tópicos de Geometria Plana, a partir 
de uma experiência desenvolvida por um grupo de pesquisa de iniciação científica do curso de Licenciatura em Matemática da Faculdade de Pará de Minas.

Santos (2008) teve como objeto de estudo a introdução do software GrafEq no ensino de Geometria Analítica no Ensino Médio, implantando uma sequência de atividades envolvendo tópicos de Geometria Analítica e o uso do recurso tecnológico.

Silva e Santos (2013) verificaram as potencialidades da aprendizagem de Geometria Plana utilizando o GeoGebra. Para tal, foram aplicadas atividades em sala de aula e na sala de tecnologia de uma escola. A utilização do software no desenvolvimento da atividade proposta promoveu um ambiente de aprendizagem mais interativo, tornando os alunos mais participativos na construção do seu conhecimento.

Vieira (2015) apresentou reflexões acerca das experiências vivenciadas pelos professores do Programa de Residência Docente (PRD) do Colégio Pedro II, Escola Federal do Município do Rio de Janeiro, em uma proposta de formação sobre o ensino de Geometria com o uso de tecnologias digitais. A prática pedagógica abordou a utilização do software SketchUp em atividades de familiarização do aplicativo e de investigação das propriedades das figuras planas e espaciais. Tal processo formativo favoreceu o aprimoramento do conhecimento profissional docente e o processo de apropriação das tecnologias digitais, uma vez que possibilitou aos professores a reconstrução de conceitos geométricos e a mobilização dos conhecimentos tecnológicos.

Os resultados apresentados pelos trabalhos anteriormente citados demonstram o potencial das tecnologias digitais no ensinar de Geometria. Os estudos dos autores evidenciam que as tecnologias agregam uma visualização menos abstrata das construções geométricas, além de estimular a curiosidade tanto de alunos quanto de professores em formação, que têm contato com alguns softwares educacionais. Logo, conclui-se que a presença das tecnologias digitais em sala de aula pode ser um potencializador no processo de construção do conhecimento por parte dos alunos.

Na próxima seção, será descrita a metodologia adotada, evidenciando o campo empírico desse estudo, que é o Curso de Especialização para Professores de Matemática, e detalhando as três atividades escolhidas para serem analisadas ao longo do mesmo.

\section{METODOLOGIA}

A metodologia consistiu na análise de três atividades propostas durante a disciplina de Geometria Analítica e Dinâmica, em que os professores, são pós-graduandos do Curso de Especialização para Professores de Matemática, ofertado pela Universidade 
Federal do Rio Grande - FURG, no âmbito da Universidade Aberta do Brasil (UAB), na modalidade a distância.

Foram escolhidas seis alunas e cinco alunos do curso para terem os seus relatos de atividades, desenvolvidas na disciplina e postadas no Moodle, analisados, sendo os 11 alunos denominados por pós-graduandos, independentemente de gênero e acompanhados de um número, a fim de garantir o anonimato nesta pesquisa. As partes mais significativas de cada relato foram sublinhadas nas caixas de texto, a fim de evidenciar os pontos mais relevantes que serão suscitados na análise.

As atividades desenvolvidas com os pós-graduandos foram as seguintes:

Atividade 1: O Potencial da Tecnologia no Ensino da Geometria: esta atividade abordou os potenciais das tecnologias no ensino da Geometria, apresentando como objeto de partida para a discussão o artigo "O uso do software GeoGebra no ensino de Geometria Analítica: experiências vivenciadas no contexto escolar ${ }^{1}$ ”, de Nascimento et. al. (2015). Em um fórum de discussões no ambiente virtual Moodle, os pós-graduandos foram instigados a responder os questionamentos ilustrados na figura 1.

\section{Atividade 1}

Qual a sua concepção em relação ao uso de tecnologias (dispositivos móveis, softwares, simuladores, entre outros...) no ensino da geometria?

Construir o triângulo retângulo e suas medidas utilizando o software GeoGebra é diferente do que usando o papel, régua e compasso? Por quê? Não seria melhor em quadro?

Figura 1 - Questões problematizadoras sobre ensinar Geometria que compuseram a atividade 1

Fonte: Os autores

Atividade 2: Erro no Ensino da Geometria: esta atividade tratou do erro no ensino da geometria, apresentando como objeto de partida para a discussão uma situação para ser analisada e respondida no fórum criado para a tarefa. Esta, por sua vez, foi a seguinte: uma aluna diz que construiu um triângulo retângulo. O professor, ao observar no software o triângulo construído pela aluna, perguntou se de fato era um triângulo retângulo, porém ela não soube responder. Utilizando uma ferramenta do software GeoGebra e medindo o

\footnotetext{
${ }^{1} \mathrm{O}$ artigo esboça experiências vividas no contexto escolar a partir da utilização do software GeoGebra no estudo introdutório de Geometria Analítica. Os resultados obtidos atestam em favor da importância e presença dos recursos tecnológicos no exercício docente, pois a utilização do software em questão proporcionou a exemplificação e demonstração do conteúdo matemático, viabilizando uma compreensão conceitual mais aguçada a partir do estímulo à curiosidade e ao interesse dos estudantes.
} 
ângulo que estava afirmando ser reto, verificou-se que o mesmo media $89,38^{\circ}$ e não $90^{\circ}$, conforme pode ser visualizado na figura 2 a seguir.

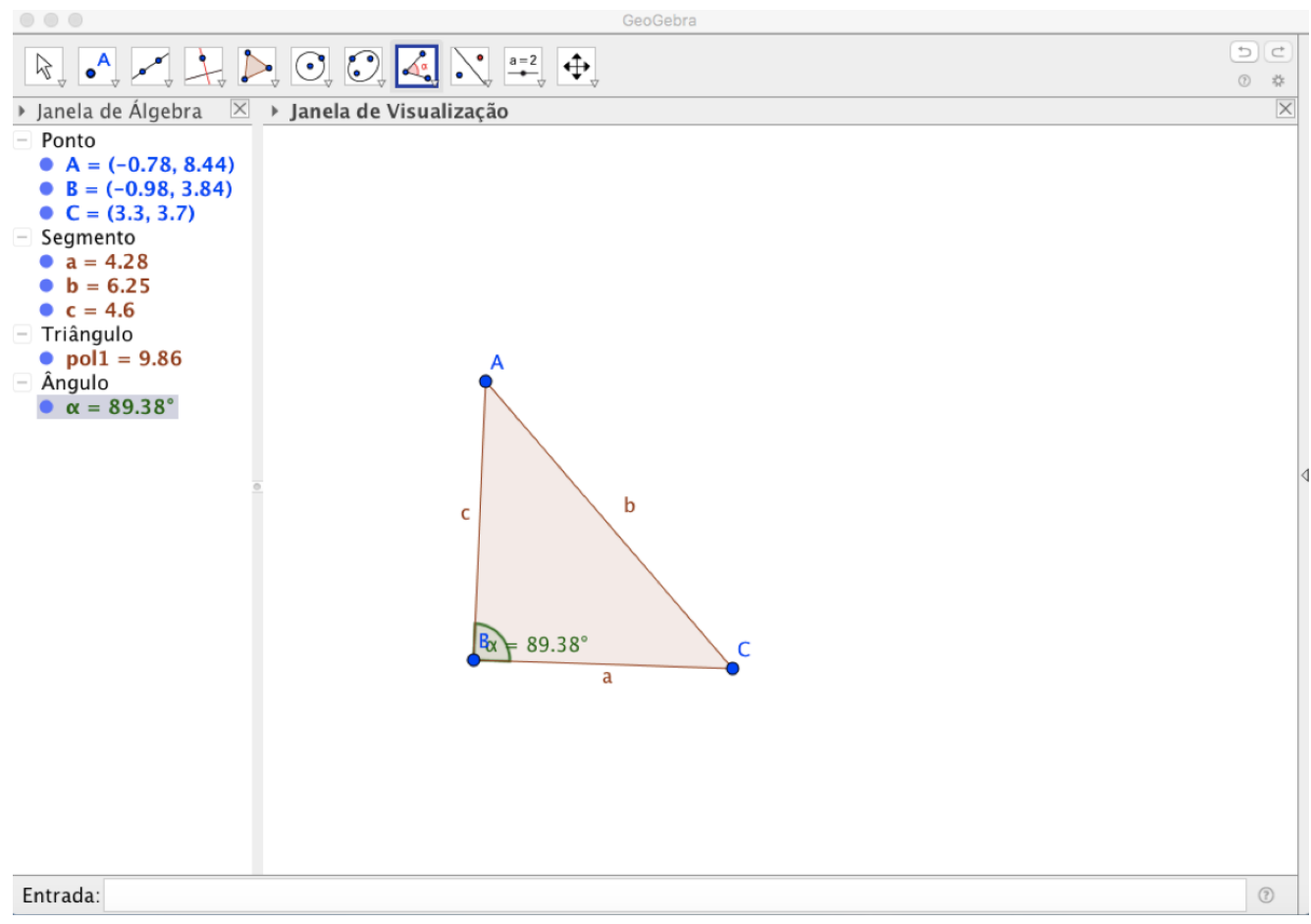

Figura 2 - Construção do triângulo retângulo feita de forma incorreta, a partir do software GeoGebra, para a atividade 2

Fonte: Plataforma Moodle.

Os pós-graduandos responderam, em um fórum de discussões no ambiente Moodle, os seguintes questionamentos:

1) O que fazer a partir desta situação? Que tipo de mediação pedagógica assumir?

2) De que forma você, como professor, pode explorar o erro da estudante para construir o conceito com ela?

Atividade 3: Problematizando o Ensino de Geometria: esta atividade apresentou como ponto de partida as reflexões de Lorenzato (1995), afirmando que ensino da geometria, quando comparado com o ensino de outras áreas da Matemática, tem sido deixado de lado, até mesmo antes do Movimento da Matemática Moderna (MMM). Os pósgraduandos responderam, em um fórum de discussões no ambiente Moodle, o seguinte questionamento: "Qual a sua percepção sobre a afirmação de Lorenzato? Que fatores podem ter contribuído para Lorenzato apontar isso?”

A partir destas três atividades, foram analisados os discursos dos pós-graduandos, buscando refletir sobre o ensino de geometria. Desta forma, nas três atividades houveram 
discursos complementares, muitas vezes ressaltando alguns pontos recorrentes em comum nas situações estudadas. Nesse sentido, podem ser definidas duas categorias, que abrangem os discursos suscitados: desafios, dificuldades e potencialidades presentes no ensino de geometria a partir de tecnologias digitais; e o ensino de geometria a partir de conceitos, construções e abstrações. Porém, salienta-se que nesse trabalho será analisada apenas a primeira categoria.

\title{
TECNOLOGIAS DIGITAIS PARA ENSINAR GEOMETRIA: POTENCIALIDADES, DIFICULDADES E DESAFIOS
}

Nas últimas décadas, as tecnologias digitais têm se tornado cada vez mais presentes no cotidiano das pessoas, com um aumento enorme na quantidade de recursos tecnológicos disponíveis. Desta forma, os estudantes, jovens que são inseridos desde muito cedo neste meio tecnológico, são extremamente acostumados a utilizar as tecnologias mais diversas em seu dia-a-dia. Prensky (2001) difundiu o termo "nativos digitais" para as pessoas nascidas a partir da década de 1980, evidenciando a presença das tecnologias digitais na vida das mesmas nos últimos anos. Aproveitando essa presença maciça, existe um grande potencial na utilização de tecnologias digitais no ensino, conforme defende Kenski (2003, p. 3), "toda aprendizagem, em todos os tempos, é mediada pelas tecnologias disponíveis".

A aprendizagem matemática, particularmente, está diretamente associada à forma como o estudante visualiza e interpreta o problema proposto a ele, conforme defende Borba et. al. (2011, p. 69):

\begin{abstract}
$\mathrm{Na}$ matemática, a visualização está associada à habilidade de interpretar e entender informações figurais. Para tanto, podem ocorrer dois processos: interpretar uma imagem visual ou criá-la a partir de uma informação não figural. A visualização é considerada, ainda, como um "processo de formação de imagens" (mentalmente, com papel e lápis, ou com outras tecnologias), usada com intuito de obter um melhor entendimento matemático e estimular o processo de descoberta matemática.
\end{abstract}

Logo, o estudante precisa construir a sua própria visualização a partir do que o problema propõe, com a finalidade de entender melhor os conceitos trabalhados e desenvolver a interpretação adequada, além de poder estabelecer conexões com o conhecimento previamente construído por ele. As tecnologias digitais apresentam-se como grandes colaboradores nesse sentido. Borba et. al. (2011, p. 89) afirma que:

O lápis e o papel moldam a maneira como uma demonstração em Matemática é feita; a oralidade realiza processo análogo quando uma ideia é amadurecida; e um software gráfico, ou uma planilha eletrônica qualquer que gera tabelas e gráficos, pode transformar o modo como um determinado assunto, ou como um tópico específico, no contexto da Matemática, por exemplo, é abordado. 
Quando o assunto é o ensino de geometria, mais se fazem presentes os recursos tecnológicos, principalmente os chamados softwares educacionais. Eles têm grande importância no processo de ensino aprendizagem por várias razões como, por exemplo, o acréscimo visual na construção geométrica. Conforme defende Nascimento (2012), a visualização geométrica é bastante facilitada a partir do uso de softwares de geometria dinâmica. A habilidade de visualizar se desenvolve à medida que o aluno passe a dispor de materiais de apoio didáticos que se baseiam em elementos concretos representativos da figura geométrica proposta.

Nesse sentido, os pós-graduandos entenderam ser fundamental o uso das tecnologias digitais no ensino de geometria, sendo um facilitador do mesmo, aproximando o problema da realidade e agregando um caráter visual à questão. Tais constatações podem ser percebidas no discurso do pós-graduando $1^{2}$ :

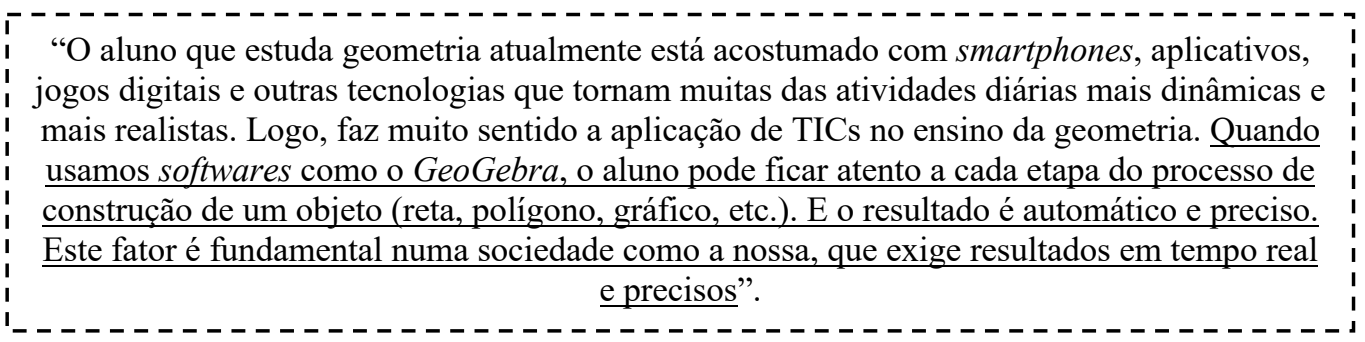

Borba e Penteado (2005) entendem que a inserção das tecnologias digitais no ambiente educativo vem sendo vista como um potencializador das ideias, buscando quebrar a hegemonia construída nas disciplinas e incentivar a interdisciplinaridade. Nesse sentido, os autores apontam algumas pesquisas envolvendo softwares de geometria dinâmica, propiciando a articulação da modelagem matemática a algumas outras áreas como a Biologia, a Física, a História e a Geografia. Assim sendo, o pós-graduando 2 compartilhou as suas reflexões:

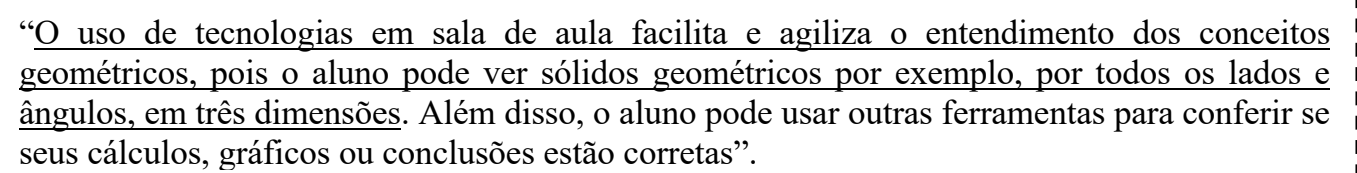

O pós-graduando declara já ter utilizado softwares e aplicativos de celular em sala de aula, obtendo resultados positivos, fazendo-o acreditar que esta interação também seja

\footnotetext{
${ }^{2}$ Os destaques em sublinhado dos discursos dos pós-graduando foram feitos pelos autores do artigo com a intenção de dar visibilidade ao que está sendo discutido.
} 
necessária para mostrar aos alunos o lado educativo da tecnologia. O pós-graduando 3 vai ao encontro do mesmo argumento:

"A construção do triângulo retângulo e suas medidas utilizando o software GeoGebra é
diferente da construção utilizando o papel, régua e compasso, pois na criação a partir do
GeoGebra, o aluno tem de conhecer não somente o conceito matemático para criar o triângulo
retângulo, mas também tem de ter conhecimento de como funciona a manipulação no software
que está utilizando".

O pós-graduando embasou seu depoimento no artigo de Nascimento et. al. (2015, p. 46), utilizando os seguintes trechos:

Consideramos que as atividades desenvolvidas pelo professor, e mediadas pelo uso de softwares matemáticos, possibilitam novos aportes exploratórios no processo de ensino/aprendizagem, contribuindo na busca pelo conhecimento qualificado, ultrapassando uma visão reducionista do ensino, pautada na memorização de regras e conceitos estáticos, sem vínculos com o contexto escolar e social, provocando desestímulo e desinteresse, culminando em sentimentos de apatia e rejeição aos saberes matemáticos. [...]. Como o mediador que adota estratégias de ensino para despertar o interesse dos educandos, contribuindo, desta forma, para a efetivação da aprendizagem matemática.

Logo, a utilização de um software matemático para construções geométricas é, de fato, diferenciada da utilização de papel, régua e compasso, que são ferramentas mais tradicionais. Ficam evidenciados os benefícios presentes na utilização dos softwares no ensino, propiciando diversas possibilidades.

No entanto, para que estes softwares sejam utilizados com finalidade pedagógica, é essencial que os professores detenham familiaridade com eles, para que os seus alunos se sintam seguros ao perceber que o professor domina a ferramenta tecnológica e esteja apto a auxiliá-los em todas as suas dúvidas - que, neste ponto, podem ser tanto conceituais quanto procedimentais, no que diz respeito ao uso do software.

Ainda que alguns pós-graduandos se mostrassem um pouco resistentes ao uso das tecnologias, eles se mostraram abertos a aprender esta forma moderna de mediar o conhecimento em um ambiente escolar. Os pós-graduandos que apresentaram mais dificuldade em utilizar uma tecnologia e pouca familiaridade com os recursos tecnológicos em geral são os mais resistentes à utilização das mesmas. No entanto, mesmo nestes casos, não foi questionada a importância das tecnologias, o que seria uma contradição enorme, partindo do princípio que o objeto de estudo são pós-graduandos de uma especialização oferecida à distância.

Um grande problema no processo de inserção das tecnologias no ambiente escolar é a falta de versatilidade dos professores com as mesmas, novamente observando o que foi discutido anteriormente: um professor que não se utiliza de tecnologias em seu dia-a- 
dia tende a não saber usar ou não gostar das mesmas. E isso, apontado pelos pósgraduandos como recorrente em seus ambientes escolares, com vários de seus colegas professores, torna mais difícil o processo de ensino aprendizagem, uma vez que os alunos não são instigados a ver a geometria de uma forma mais ampla. Silveira (2017, p. 47) aborda a questão da presença das tecnologias na formação de professores da seguinte forma:

Se a formação priorizar a efetivação de práticas e técnicas que contemplem o operar dos artefatos tecnológicos, acreditamos que as disciplinas podem se tornar espaços para pensar, organizar, analisar, interagir, refletir e tomar decisões sobre a futura profissão. Isso pode originar uma mudança na cultura, que não nega os artefatos anteriores, mas cria uma recorrência na forma de agir que inclui às tecnologias digitais, construindo uma cultura digital.

Os pós-graduandos demonstraram entender que as tecnologias devem se fazer presentes na qualificação profissional, tanto em suas graduações, quanto na formação continuada dos professores. Tais impressões ficam nítidas em alguns depoimentos, como o pós-graduando 1 , que colocou as suas ideias da seguinte forma:

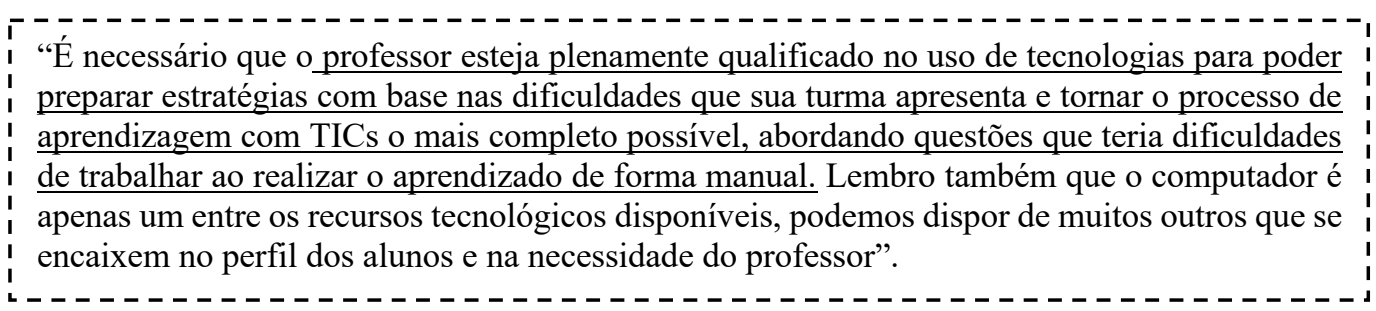

Percebe-se uma defasagem grande no que diz respeito ao preparo dos professores com o uso de ferramentas tecnológicas desde a sua formação inicial. Tal formação, por sua vez, mostra-se solidificada no tempo, ignorando o acréscimo educacional que as tecnologias podem oferecer, como discute Gatti (2010, p. 1357):

\begin{abstract}
Adentramos o século XXI em uma condição de formação de professores nas áreas disciplinares em que, mesmo com as orientações mais integradoras quanto à relação "formação disciplinar/formação para a docência", na prática ainda se verifica a prevalência do modelo consagrado no início do século XX para essas licenciaturas [...].
\end{abstract}

O despreparo dos professores com relação à manipulação de ferramentas tecnológicas decorre do fato de muitos destes não as utilizarem em seu dia-a-dia, principalmente comparando com a forma com a qual estas ferramentas são utilizadas pelos estudantes desta geração digital. Vários pós-graduandos manifestaram opiniões corroborando com estas ideias, como por exemplo o pós-graduando 4 :

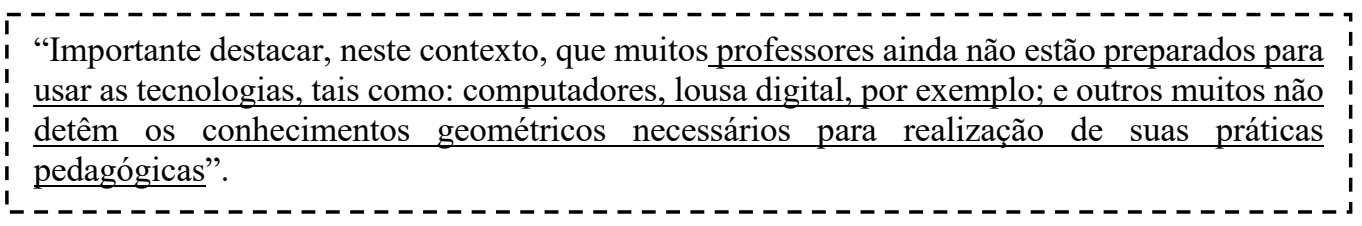


Esta falta de familiaridade e despreparo que ficam evidenciados em muitos professores não é dada somente pelo desuso das tecnologias digitais em seus cotidianos, mas também pela ausência das mesmas dentro dos ambientes escolares, logo, tal ausência pode tornar-se um complicador no processo de aprender. Como discute Costa et. al. (2016), as condições encontradas nas escolas públicas acabam desmotivando os professores e também os alunos.

Muitos dos pós-graduandos citaram ser este o principal problema encontrado por eles próprios em seus ambientes de trabalho; por vezes existe a boa vontade por parte do professor e até a familiaridade do mesmo com as tecnologias educacionais, mas ele esbarra na falta de recursos que a escola provém.

Além das escolas disporem aos seus professores e alunos as condições necessárias em termos de infraestrutura, também se faz necessário que os professores façam bom uso dos recursos disponíveis. Os pós-graduandos concordaram que fazer uso de tecnologias não é somente utilizar um computador, mas especificamente tratando-se de geometria, que é a disciplina em questão, a forma visual que um software como o GeoGebra proporciona dificilmente é equiparada por um desenho abstrato em um quadro negro.

O GeoGebra, sendo um software matemático bastante difundido no meio educacional devido às suas inúmeras interfaces de aplicação entre vários conteúdos matemáticos, propicia uma visualização mais clara das construções geométricas e as suas conexões com outros conceitos matemáticos. Carlos e Müller (2013) analisam as contribuições do GeoGebra na aprendizagem dos conceitos geométricos, como as pirâmides, defendendo que a utilização deste software propicia uma aprendizagem mais prazerosa e interativa aos alunos. Nascimento (2012) também reflete sobre o uso do GeoGebra no ensino de geometria, entendendo que o mesmo caracteriza uma ferramenta bastante útil, especialmente pela facilidade manipulativa que ele apresenta, além de ser de fácil acesso (gratuito e disponível para baixar online) ${ }^{3}$.

No entanto, outro problema bastante citado pelos pós-graduandos seria a falta de domínio do GeoGebra por parte dos estudantes, extrapolando a questão conceitual. Desta forma, caberia como solução uma retomada nas funções do software, estimulando os estudantes a trabalharem de outras formas com ele, com a finalidade de dominar os comandos básicos e assim manipular as características presentes na construção da figura em questão.

\footnotetext{
${ }^{3}$ Disponível em: https://www.geogebra.org/download
} 
Neste ponto, cabe ressaltar a seguinte questão, levantada anteriormente. Para que a retomada a partir do software seja adequada e efetiva, é primordial que o professor esteja preparado para tal, apresentando amplo domínio do mesmo. Uma vez que haja o preparo do professor, ele poderá auxiliar de forma mais efetiva os seus alunos nas questões procedimentais que envolvam a utilização da tecnologia digital. Assim sendo, o pós-graduando 3 colocou as suas ideias da seguinte maneira:

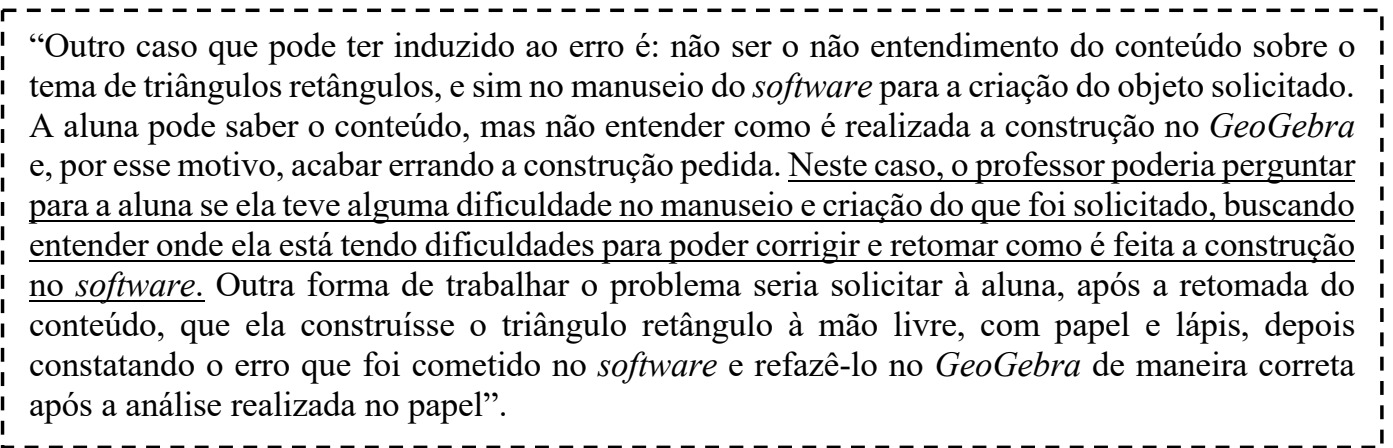

A importância do GeoGebra não é restrita à educação básica, uma vez que na formação inicial dos professores de Matemática, este software pode apresentar-se como uma importante ferramenta de construções geométricas mais avançadas, além do viés educacional. Alguns autores discutem os benefícios da utilização do GeoGebra na formação de professores de Matemática. Cotic (2012) coloca este software educacional como um grande facilitador na construção geométrica, fugindo de aspectos mais teóricos e imprecisos em termos de visualização, defendendo o seu potencial e a importância que este seja abordado desde a formação inicial dos professores, evitando que os mesmos não se sintam familiarizados com o recurso.

Leite e Oliveira (2016) também atestam em favor do GeoGebra na formação inicial, investigando de que forma os professores em formação se apropriam do conhecimento geométrico a partir do GeoGebra. Os autores ainda afirmam que identificaram diversos conhecimentos mobilizados a partir da utilização do GeoGebra em um curso de extensão, direcionado a professores em formação.

No entanto, o questionamento que surge é o seguinte: será que nas formações de professores é dada a devida atenção à utilização de softwares e tecnologias educacionais, mais especificamente, o GeoGebra na Educação Matemática? Segundo o pós-graduando 11, o GeoGebra, apesar de todo o potencial que tem, é pouco explorado: estilizar o GeoGebra seria interessante, pois estudei com ele durante a faculdade e agora na
em uma vi uma professora fazer uso deste software, com turmas de nono ano e só. Não lembro
em nenhum livro didático que relate ser possível trabalhar com o GeoGebra, portanto, onde
encontramos planos de aulas com tais relações?" 
É possível citar também outras ferramentas tecnológicas, que não sejam particularmente o GeoGebra ou mesmo um software educacional. Alguns pósgraduandos colocaram que existe um potencial em diversas tecnologias digitais que por vezes nem são consideradas educativas, ou ao menos não têm finalidade pedagógica para a área da Matemática. $O$ pós-graduando 10 compartilhou exatamente estas ideias:

"Já para as séries finais e o Ensino Médio, o uso de tecnologias de softwares, a elaboração de
vídeos, o processo de criação de desenhos e a fotografia são recursos interessantes para
auxiliarem o ensino da geometria. Não podemos deixar em segundo plano uma das áreas que
mais contribui de forma concreta para o mundo que conhecemos a nossa volta. Se faz necessário
incluir sempre a geometria".

Dessa forma, percebe-se que é importante que o professor, desde o seu processo de formação inicial, esteja preocupado com a contextualização no ensinar da geometria, uma vez que a representação desta área do conhecimento no nosso dia-a-dia é enorme. Para isto, é preciso que ele tenha contato com as tecnologias digitais desde a sua formação, além de importar-se com o potencial educacional presente nelas. Não significa que as tecnologias precisam, necessariamente, substituir outros recursos mais tradicionais como o quadro, giz, régua, compasso e lápis. Uma abordagem interessante seria ponderar a utilização mútua de ambas metodologias de ensino, entendendo que há inúmeros pontos positivos nas duas formas.

\section{RETOMANDO O TEMA}

Este artigo partiu da reflexão da importância do uso de tecnologias digitais no ensino de geometria, devido ao potencial educativo que elas oferecem na visualização das construções geométricas. Sendo assim, pensar na formação dos professores para manipular os artefatos tecnológicos em sala de aula, desde a sua formação inicial é fundamental. Esse fato fica evidente nos relatos dos pós-graduandos que acreditam no potencial das tecnologias digitais, diferenciando o ensino de geometria feito a partir de uma abordagem mais tradicional, com régua, compasso, lápis, papel, quadro e giz. Ambas metodologias têm seus potenciais e falhas, sendo complementares no processo de aprendizagem dos alunos.

Porém, há a necessidade de haver uma preparação na formação inicial de professores, as licenciaturas precisam dispor de disciplinas que potencializem os graduandos a ensinarem a geometria. Deste modo, as discussões originadas na disciplina de Geometria Analítica e Dinâmica do Curso de Especialização para Professores de Matemática transcenderam os conceitos geométricos, de uma forma mais pura; elas 
consistiram também nas reflexões acerca das práticas docentes com relação à geometria, uma vez que os pós-graduandos são, em sua grande maioria, professores de Matemática atuantes na área.

Por fim, espera-se que as falas apresentadas neste trabalho, em conjunto com as reflexões originadas e a partir de alguns referenciais teóricos consultados, evidenciem a importância do ensino de Geometria em sala de aula, desde a formação básica dos professores, até a apropriação do conhecimento por parte dos alunos, mediada pelo professor.

\section{REFERÊNCIAS}

BORBA, M. C.; et. al. Educação à Distância Online. $3^{\text {a }}$ edição, Autêntica, Belo Horizonte, 2011.

BORBA, M. C.; PENTEADO, M. G. Informática e Educação Matemática. Autêntica, Belo Horizonte, 2005.

CARlOS, M. L.; MÜLLER, T. J. A Contribuição do Software GeoGebra na Aprendizagem dos Conceitos Geométricos no Estudo das Pirâmides. In: VI Congresso Internacional de Ensino da Matemática. Canoas, outubro de 2013.

COSTA, V. A. F.; et. al. O Ensino da Matemática e a Falta de Infraestrutura nas

Escolas Brasileiras. In: III Congresso Nacional de Educação. Salvador, agosto de 2016.

COTIC, N. GeoGebra na Formação Docente. In: $1^{\text {a }}$ Conferência Latino Americana de GeoGebra, p. CCXXX-CCXL, 2012.

GATTI, B. A. Formação de Professores no Brasil: Características e Problemas. In: Educação Social, vol. 31, n. 113, p. 1355-1379. Campinas, outubro-dezembro de 2010.

KENSKI, V. M. Aprendizagem Mediada pela Tecnologia. In: Revista Diálogo Educacional, vol. 4, n. 10, p. 1-10, setembro-dezembro de 2003.

LEITE, R. S.; OLIVEIRA, G. P. Formação de Professores e GeoGebra: Uma Proposta para Compreender e Ensinar o Teorema de Tales. In: XII Encontro Nacional de Educação Matemática. São Paulo, julho de 2016.

LORENZATO, S. Por que não Ensinar Geometria? In: Educação Matemática em Revista, SBEM, n. 4, p. 3-13, 1995.

NASCIMENTO, E. G. A. Avaliação do uso do Software GeoGebra no Ensino de Geometria: Reflexão da Prática na Escola. In: Actas de La Conferencia Latino Americana de GeoGebra, p. 125-132. Uruguai, 2012.

NASCIMENTO, F. J.; et. al. O uso do Software GeoGebra no Ensino de Geometria Analítica: Experiências Vivenciadas no Contexto Escolar. In: Educação Matemática em Revista, SBEM, p. 40-47, 2015.

PRENSKY, M. Digital Natives, Digital Immigrants. On The Horizon, NCB University Press, vol. 9, n. 5, outubro de 2001. 
SANTOS, A. S.; et. al. Tecnologia a Favor da Educação Matemática: GeoGebra e suas Aplicações. In: VII Encontro Mineiro de Educação Matemática. Juiz de Fora, outubro de 2015.

SANTOS, R. S. Tecnologias Digitais na Sala de Aula para Aprendizagem de Conceitos de Geometria Analítica: Manipulações no Software GrafEq. Dissertação de Mestrado, Programa de Pós-Graduação em Ensino de Matemática. Universidade Federal do Rio Grande do Sul (UFRGS), Porto Alegre, 2008.

SILVA, A. Q.; SANTOS, T. S. O Uso do Software GeoGebra no Ensino de Geometria Plana. In: VI Congresso Internacional de Ensino da Matemática. Canoas, outubro de 2013.

SILVEIRA, D. S. Redes de Conversação em uma Cultura Digital: um Modo de Pensar, agir e Compreender o Ensino de Matemática na Educação Superior. Tese de Doutorado, Programa de Pós-Graduação em Educação em Ciências: Química da Vida e Saúde. Universidade Federal do Rio Grande (FURG), Rio Grande, 2017.

VIEIRA, E. R. Ensino de Geometria com Tecnologias Digitais: Experiências dos Professores do Programa de Residência Docente do Colégio Pedro II. In: VI Seminário de Mídias \& Educação do Colégio Pedro II, n. 1. Rio de Janeiro, 2015.

Submetido em 29 de setembro de 2019. Aprovado em 21 de janeiro de 2020. 